\title{
Anti-proliferative and Apoptosis Inducing Activity of Lactobacillus brevis OPK-3 Isolated from Kimchi on Leukemia Cell Lines
}

\author{
Ki-Bum Park ${ }^{1,2}$, Chan-Ho $\mathrm{Oh}^{1}$, and Suk-Heung $\mathrm{Oh}^{1 *}$ \\ ${ }^{1}$ Department of Food \& Biotechnology, Woosuk University, Jeonju 565-701, Korea \\ ${ }^{2}$ Research and Development center, DAYOU WINIA Co., Ltd., Asan 336-843, Korea
}

\begin{abstract}
In the present work we investigated the effects of lactic acid bacteria (LAB) isolated from kimchi on proliferation and apoptosis of cancer cells. The cell-free supernatant concentrate of Lactobacillus brevis OPK-3 significantly retarded the proliferation of human acute promyelocytic (HL60), human histiocytic (U937), and mouse lymphocytic (L1210) leukemia cell lines in vitro at concentrations over $2.25-9.0 \mathrm{mg} / \mathrm{mL}$. The treatments of the concentrate leaded to the increased apoptosis and decreased mitochondrial transmembrane potential in cultured U937 leukemia cell lines. In addition, the treatments of the concentrate showed the increased expression of p53 gene in cultured U937 and HL60 leukemia cell lines. On the other hand, the cell-free supernatant concentrate of control L. brevis strain (KCCM 41028) showed a relatively little effect on the cancer cell proliferation, apoptosis, and mitochondrial transmembrane potential at the similar concentration ranges compared with the $L$. brevis OPK-3 samples. These results suggest that the consumption of $L$. brevis OPK-3 could be beneficial for the inhibitory action on leukemia cell proliferation and for the stimulatory action on the cancer cell apoptosis.
\end{abstract}

Keywords: Lactic acid bacteria, cancer cell, growth, inhibition, apoptosis

\section{Introduction}

Kimchi is a well-known Korean traditional fermented food. Cabbage kimchi is rich in lactic acid bacteria (LAB) which are the major group of bacteria that can grow in kimchi. Lactobacillus plantarum, Lactobacillus brevis, Leuconostoc mesenteroides, Streptococcus faecakis, Weissella koreensis and Pediococcus pentosaceus are the dominant species of LAB found in Cabbage kimchi (Kim, 2005; Kim et al., 2005; Lee et al., 2002; Park and Oh, 2004; Park and Oh, 2005; Yu et al., 2009). The anticarcinogenic, immunomodulatory, antimicrobial, antidiarrheal and anti-allergy activities of kimchi LAB have been reported by several authors so far (Hur et al., 2006; Kim, 2005; Kim et al., 2005). Kimchi LABs are beneficial inhabitants of the intestines of humans and animals (Aguirre and Collins, 1993; Kim, 2005; Park and Oh, 2004). Consumption of $300 \mathrm{~g}$ of kimchi a day, raises the colonic lactic acid bacteria 100 times more in Kimchi eater than the non eater. Thus, kimchi provides a suitable

\footnotetext{
*Corresponding author: Suk-Heung Oh, Department of Food \& Biotechnology, Woosuk University, Jeonju 565-701, Korea Tel: 82-63-290-1433, Fax: 82-63-290-1429

E-mail: shoh@woosuk.ac.kr; shoh1573@yahoo.co.kr Received March 28, 2015; Revised April 10, 2015; Accepted April 25, 2015
}

environment for the growth of LAB in the intestine where as it inhibits the flourishment of pathogenic bacteria and viruses in the gastrointestinal tract (Park and Oh, 2004). Kimchi LAB secretes two types of medicinal amino acids namely are $\gamma$-aminobutyric acid (GABA) and ornithine as secondary metabolites in the culture media (Oh et al., 2010; Park and Oh, 2005; Park and Oh, 2006; Seok et al., 2008; Yu et al., 2009).

GABA is produced primarily by the $\alpha$-decarboxylation of L-glutamic acid (Glu) catalyzed by the enzyme glutamate decarboxylase (GAD) (Ueno, 2000). The role of GABA in animals has been well understood as an inhibitory neurotransmitter with hypotensive and analgesic properties (Krogsgaard-Larsen, 1989; Mody et al., 1994). It has also been reported that GABA has an improving effect of visual perception in older animals (Leventhal et al., 2003). Ornithine is frequently used in the U.S. as a food supplement as well as anti-obesity agent (Elam et al., 1988; Leventhal et al., 2003). L-ornithine is also widely used as an anabolic material for muscle development (Wernerman et al., 1987) and immunity improvement (Kawai et al., 1999; Kawai et al., 2000; Robinson et $a l ., 1999)$ in the form of L-ornithine- $\alpha$-Ketoglutaric Acid (OKG) that contains L-ornithine and $\alpha$-ketoglutaric acid in the ratio of 2:1. Many LAB from fermented foods such as kimchi, wine and cheese produce ornithine by the trans- 
formation of arginine via the arginine deiminase (ADI) pathway or the arginase-urease pathway (Arena et al., 1999; Kuensch et al., 1974; Liu et al., 2003). Accumulating data suggested that the transformation of arginine by these enzymes are cytotoxic to cancer cells (Ensor et al., 2002; Kim et al., 2009; Rijn et al., 2003).

We isolated LAB species $L$. brevis OPK-3 with GABA and ornithine producing capacities (Oh et al., 2010; Park and Oh, 2006; Park and Oh, 2007) and Lactobacillus sakei OPK2-59 with GABA producing capacities (Bae et al., 2009; Seok et al., 2008; Yu and Oh, 2011) from fermented foods such as kimchi (Bae et al., 2009). Previously, we reported that $L$. sakei OPK2-59 culture lyophilized powder supplementation improves serum lipid and lipid catabolic enzyme profiles in rats administered with ethanol (Bae et al., 2009). Genetically engineered Bacillus subtilis with an insert of $L$. brevis OPK-3 derived GAD gene, improved the functional characteristics in Bacillus subtilis (Park and Oh, 2006). Several authors reported that GABA has anti-proliferative activities in cancer cells and also it significantly increases apoptosis in cancer cells (Fava et al., 2005; Joseph et al., 2002; Sun et al., 2003; Tatsuta et al., 1992).

Therefore, we were interested to investigate whether kimchi LAB with GABA and ornithine producing capacities can affect the proliferation and apoptosis of cancer cells.

\section{Materials and Methods}

\section{Cell culture}

Human acute promyelocytic (HL60), human histiocytic (U937), and mouse lymphocytic (L1210) cell lines were provided from Korea Cell Line Bank (KCLB, Seoul, Korea). The cells were maintained in RPMI 1640 medium (Gibco BRL, Gaithersburg, MD) supplemented with $10 \%$ fetal bovine serum (FBS). Cells were grown at $37^{\circ} \mathrm{C}$ in a humidified atmosphere with $5 \% \mathrm{CO}_{2}$ until reaching approximately $70-80 \%$ confluence.

\section{Bacterial strain and materials}

L.brevis OPK-3 (KFCC 11330) with high GABA and ornithine producing capacityes (Oh et al., 2010; Park and Oh, 2007) and L. brevis (KCCM 41028) with low the capacities (Seok et al., 2008) were used for the present study. Difco MRS medium (Detroit, MI, USA) was used for bacterial cell cultures. The LAB were cultured in MRS media supplemented with $1 \%(\mathrm{w} / \mathrm{v})$ monosodium glutamate (MSG) for $3 \mathrm{~d}$ at $37^{\circ} \mathrm{C}$. Cells were collected by cen- trifugation at $1,250 \mathrm{~g}$ for $20 \mathrm{~min}$ at $4^{\circ} \mathrm{C}$. The cell-free supernatants were filtered through $0.45 \mu \mathrm{M}$ sterile filter (Millipore, Bedford, MA, USA) and freeze dried. The powders were dissolved in double distilled water, syringe filtered and used for the analyses of GABA and anti-cancer activities.

\section{Analysis of GABA}

GABA was extracted essentially as described by Baum et al. 1996. GABA content in samples was analyzed by HPLC (Waters, USA) as described Park and Oh, 2005, 2006 and was calculated using the Autochro WIN program (Young-Lin, Korea) and expressed as an average value of the triplicate analyses.

\section{Effects of the LAB culture supernatants on the proliferation of leukemia cells}

Human acute promyelocytic (HL60), human histiocytic (U937), and mouse lymphocytic (L1210) leukemia cell lines were seeded at a density of $5 \times 10^{4}$ cells /well and were treated with the LAB culture cell-free supernatants at concentrations of $2.25,4.5$, and $9 \mathrm{mg} / \mathrm{mL}$ followed by incubation in $\mathrm{CO}_{2}$ incubator at $37^{\circ} \mathrm{C}$. After $48 \mathrm{~h}$ of incubation, 3-(4,5-dimethylthiazol-2-yl)-2,5-diphenyltetrazolium bromide (MTT, final concentration, $0.5 \mathrm{mg} / \mathrm{mL}$ ) was added, and then incubations were continued for further 4 $\mathrm{h}$ (Mosmann et al., 1983). To dissolve formazan, $100 \mu \mathrm{L}$ of dimethyl sulforxide (DMSO) was added to each well and the OD of each well was read using ELISA reader (Molecular Devices, Sunnyville, CA).

\section{Effect of the LAB culture supernatants on the apo- ptosis of $\mathrm{U} 937$ cells in vitro}

U937 cells were treated with the LAB culture cell-free supernatants ( 4.5 and $9 \mathrm{mg} / \mathrm{mL}$ ) and incubated for $24 \mathrm{~h}$ at $37^{\circ} \mathrm{C}$. Detection of apoptosis by flow cytometry was performed using propidium iodide (PI). The staining was performed according to the producer's manual. Cells were analyzed Sub G1 peak using a flow cytometer (Coulter: Epics- XL, Miami, FL, USA).

\section{Effect of the LAB culture supernatants on the mito- chondrial transmembrane potential of U937 leuke- mia cells}

U937 cell line was seeded at a density of $1 \times 10^{6}$ cells/ well. LAB culture cell-free supernatants were added into the cultures at concentrations of $2.25,4.5$ and $9 \mathrm{mg} / \mathrm{mL}$ and cultured for $24 \mathrm{~h}$ at $37^{\circ} \mathrm{C}$. The cells were collected and mitochondiral transmembrane potential was measured by 
a flow cytometer staining with DiOC6 (final Conc. 40 $\mathrm{nM}$ ) for $15 \mathrm{~min}$ (excitation: $488 \mathrm{~nm}$, emission: $525 \mathrm{~nm}$ ).

\section{Effect of the LAB culture supernatants on p53 gene expression in U937 and HL60 cells}

U937 and HL60 cells were treated with LAB culture cell-free supernatants $(9 \mathrm{mg} / \mathrm{mL})$ and incubated in a $\mathrm{CO}_{2}$ incubator at $37^{\circ} \mathrm{C}$. After $24 \mathrm{~h}$ incubation, total RNA was isolated from the samples using Trizol (Invitrogen, Carlsbad, CA, USA). The RNA extraction was performed according to the producer's manual. cDNA synthesis was performed for $30 \mathrm{~min}$ at $50^{\circ} \mathrm{C}$ using oligo dT primer. The initial PCR step was activated by heating for $15 \mathrm{~min}$ at $95^{\circ} \mathrm{C}$ before PCR $\left(30 \mathrm{~s}\right.$ denaturation at $94^{\circ} \mathrm{C}, 30 \mathrm{~s}$ annealing at $57^{\circ} \mathrm{C}, 30 \mathrm{~s}$ extension at $72^{\circ} \mathrm{C}, 35$ cycles) using a PCR Thermal cycler Dice (Takara, Japan). The PCR products were identified on a $1 \%(\mathrm{w} / \mathrm{v})$ agarose gels. PCR reactions were performed using p53 primers: sense (5'CCT CCT GGC CCC TGT CAT CT-3'), anti-sense (5'ACA AAC ACG CAC CTC AAA GC -3').

\section{Statistical analysis}

Data from an individual experiment were described as a mean \pm standard deviation. All statistical analyses were performed on a statistical analysis system (SAS) program, and significant difference between mean values was determined by using Student's t-test that $p<0.05$ was judged to be statistically significant.

\section{Results}

The cell-free supernatants concentrates $(22.5-90.0 \mathrm{mg}$ / $\mathrm{mL}$ ) of LAB were prepared using L. brevis OPK-3 (KFCC 11330 ) and L. brevis (KCCM 41028) strains. The concentrates of L. brevis OPK-3 (KFCC 11330) and L. brevis (KCCM 41028) were standardized based on the contents of GABA determined using HPLC after 6-aminoquiolyN-hydroxysuccinimidyl carbonate (AQC) derivatization. GABA was found in the concentrates of $L$. brevis OPK-3 and L. brevis (KCCM 41028) at the levels of 10-40 $\mu \mathrm{g} /$ $\mathrm{mL}$ and $0.005-0.02 \mu \mathrm{g} / \mathrm{mL}$, respectively.

To test the anti-cancer activities of the concentrates, human acute promyelocytic (HL60), human histiocytic (U937), and mouse lymphocytic (L1210) leukemia cells were treated with the LAB concentrates at the concentrations of $2.25 \mathrm{mg} / \mathrm{mL}, 4.5 \mathrm{mg} / \mathrm{mL}$, and $9.0 \mathrm{mg} / \mathrm{mL}$, and incubated for $48 \mathrm{~h}$, followed by proliferation and apoptosis of cancer cells were assayed. As shown in Fig. 1, the samples of $L$. brevis OPK-3 at concentrations over 2.25-
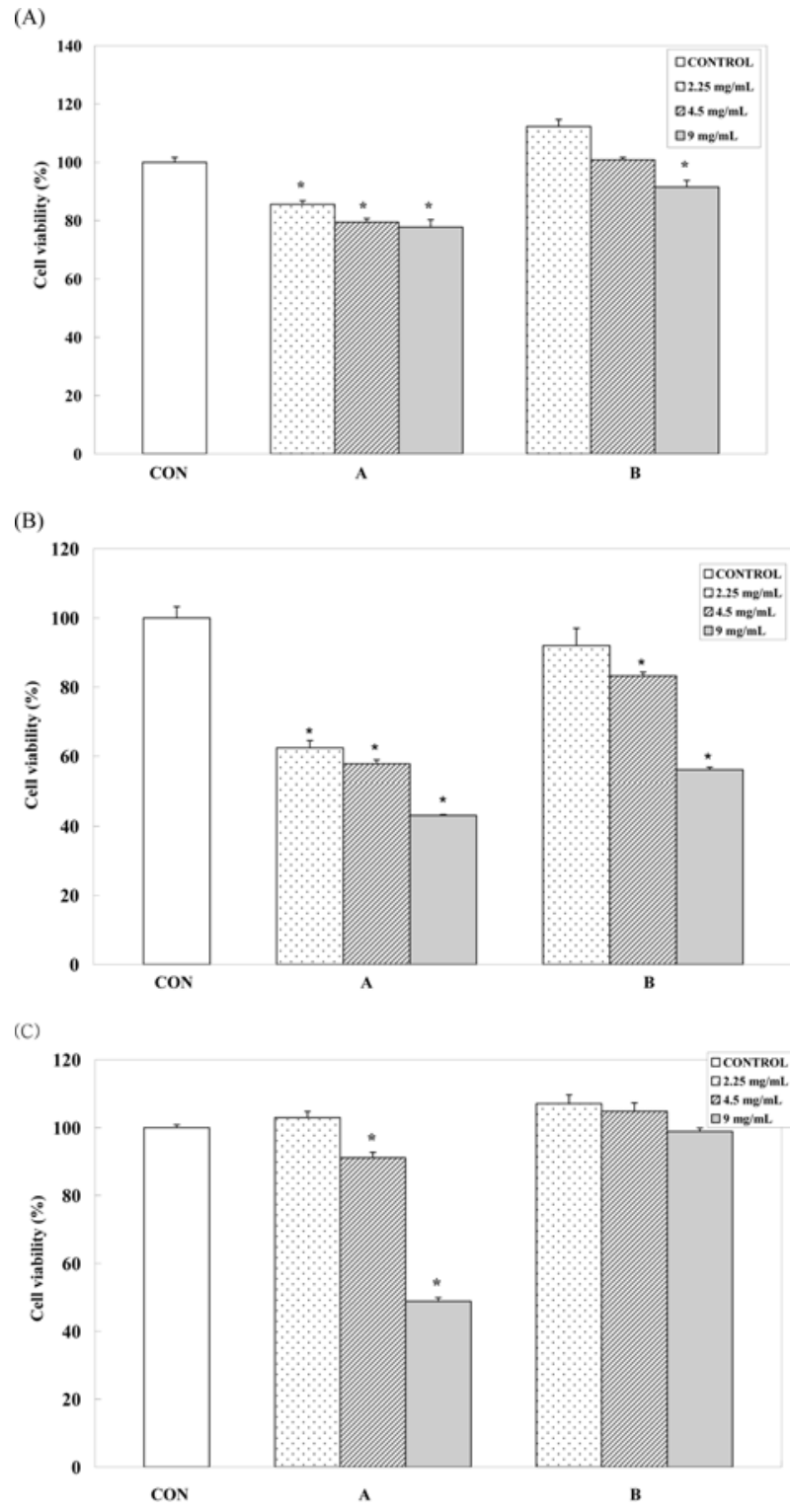

Fig. 1. Effect of the LAB samples on the proliferation of HL60 (human acute promyelocytic) (A), U937 (human histiocytic) (B), L1210 (mouse lymphocytic) (C) leukemia cell lines in vitro. The LAB samples were added to the various cultured leukemia cell lines at the indicated concentration and cultured for $48 \mathrm{~h}$ at $37^{\circ} \mathrm{C}$. The proliferation of the cells was assayed by the MTT method. The O.D of each well was measured at $570 \mathrm{~nm}$ with a microplate reader. Each bar represents the mean $\pm \mathrm{SD}$ of three experiments. CON; leukemia cell line without LAB sample treatment. A, L. brevis OPK-3 sample; B, L. brevis KCCM 41028 sample. *Significantly different from control group $\left({ }^{*} p<0.05\right)$.

$9.0 \mathrm{mg} / \mathrm{mL}$ significantly retarded the proliferation rates of all tested leukemia cells compared with $\mathrm{CON}$ or control L. brevis sample. These results show that cell-free concentrates of the L.brevis OPK-3 culture inhibits cell pro- 


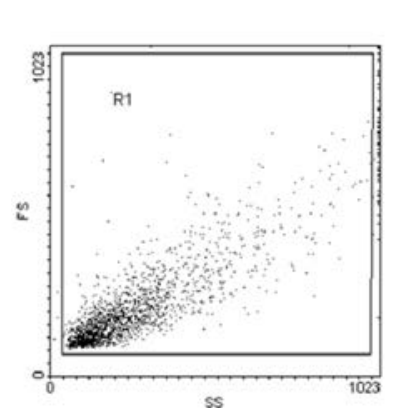

A-4.5mg/mL

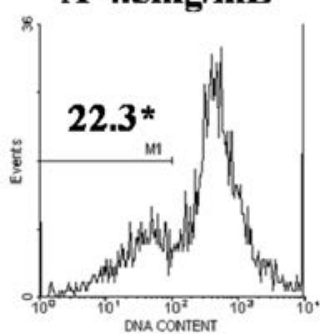

B-4.5mg/mL

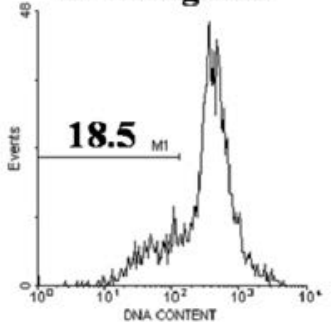

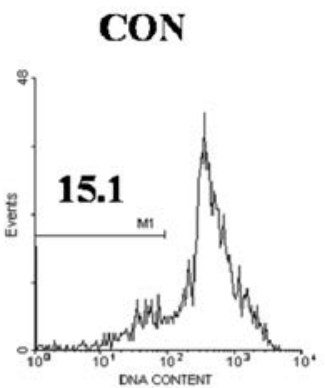

A-9mg/mL

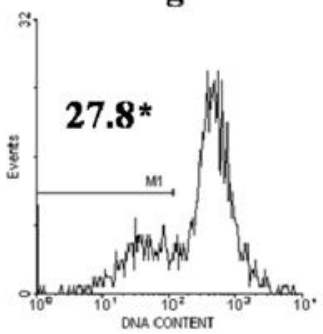

B-9mg/mL

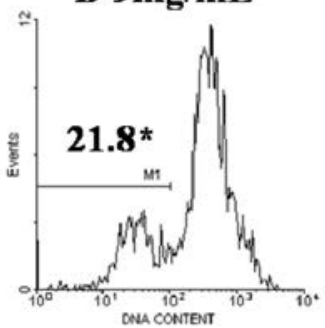

Fig. 2. Effect of the LAB samples on the Sub G1 peak of U937 cells in vitro. The $\mathrm{LAB}$ samples were added into the cultured U937 cells at the indicated concentration and cultured for $24 \mathrm{~h}$ at $37^{\circ} \mathrm{C}$. The apoptosis of the cells was assayed by flow cytometric analysis. Each values represent the mean of three experiments. CON; leukemia cell line without LAB sample treatment. A, L. brevis OPK-3 sample; B, L. brevis KCCM 41028 sample. *Significantly different from control group $\left({ }^{*} p<0.05\right)$.

liferation in wide range of leukemia cell lines.

To further investigate the effects of the LAB concentrates on anti-cancer activity, we treated U937 leukemia cells with the concentrates and measured Sub G1 peak and mitochondrial transmembrane potential (MMP) in these cells. As shown in Figs. 2 and 3, U937 cells treated with the concentrates of $L$. brevis OPK-3 culture demonstrated a significantly increased in Sub G1 peak and decreased MMP levels comparing with untreated cells and cells treated with control concentrates. L1210 cells showed a similar pattern in the Sub G1 peak and MMP levels (data not shown). These data suggests that the cell-free supernatant concentrates of $L$. brevis OPK-3 culture effectively induce apoptosis in U937 leukemia cells. The enhanced apoptosis of the leukemia cells could be one of the under-

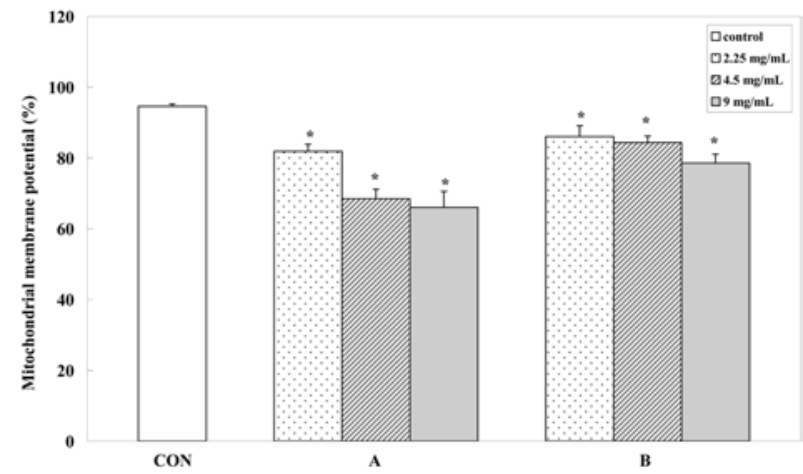

Fig. 3. Effect of the LAB samples on mitochondrial transmembrane potential in U937 leukemia cells. The suspension of cells was prepared at $1 \times 10^{6}$ cells/well. The LAB samples were added into the cultures at the indicated concentration and incubated for $24 \mathrm{~h}$ at $37^{\circ} \mathrm{C}$. The cells were collected and MTP was measured by a flow cytometer staining with DiOC6 (40nM). The each bar represents the mean \pm standard deviation of three experiments. $\mathrm{CON}$; leukemia cell line without LAB sample treatment. A; $L$. brevis OPK-3 sample; B, L. brevis KCCM 41028 sample. *Significantly different from control group $\left({ }^{*} p<0.05\right)$.

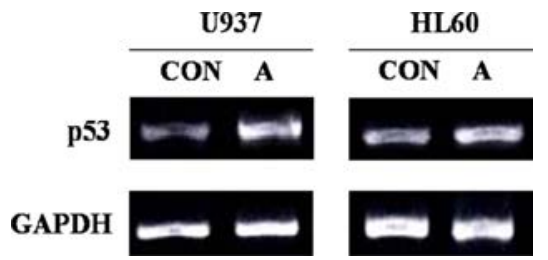

Fig. 4. Effect of the LAB samples on p53 gene expression in U937 and HL60 cells. The LAB samples were added to the various cultured leukemia cells for $24 \mathrm{~h}$ at $37^{\circ} \mathrm{C}$. CON; cell lines without sample treatment. A; cell lines treated with the L. brevis OPK-3 samples $(9 \mathrm{mg} / \mathrm{mL})$. GAPDH, glyceraldehyde-3-phosphate dehydrogenase.

lying reasons for the anticancer activities of the concentrates.

To investigate the effects of the cell-free supernatant concentrates on p53 gene expression, we treated U937 and HL60 cells with the concentrates and measured the expression of $\mathrm{p} 53$ gene by RT-PCR analysis. As shown in Fig. 4, the treatment of cell lines with the concentrates of L. brevis OPK-3 culture showed an enhanced expression of p53 gene compared with untreated cells.

\section{Discussion}

In this present study, we have investigated the effects of the cell-free supernatant concentrate of $L$. brevis OPK-3 
culture on proliferation and apoptosis of cancer cells. The concentrates from $L$. brevis OPK-3 culture showed antiproliferation and apoptosis activities on the cancer cell lines; human acute promyelocytic (HL60), human histiocytic (U937), and mouse lymphocytic (L1210) leukemia cells. On the other hand, control concentrates of L. brevis (KCCM 41028) culture showed a relatively little effects on the cancer cell lines.

It has been reported that both the culture medium and live whole cells from probiotic strains can have anticancer effects. For example, culture medium and live whole cells of Enterococcus faecium RM11 and Enterococcus fermentum RM28 isolated from fermented dairy milks triggered anti-proliferation of colon cancer cells at the rates of $21-29 \%$ and $22-29 \%$, respectively (Thirabunyanon et al., 2009). The cell-free supernatants of Lactobacillus acidophilus 74-2 upregulated cyclo-oxygenase (COX)-1 in gastric cancer cells showing an anticancer potential (Mahkonen et al., 2008). Probiotic effects of kimchi LAB has also been reported (Hur et al., 2006; Kim, 2002; Kim, 2005; Kim et al., 2005). For example, Lactobacillus plantarum showed immunopotentiating and antimutagenic activities (Hur et al., 2006; Rhee and Park, 1999). However, little is known on the mechanism and the products underlying the probiotic effects of kimchi LAB.

One of the underlying possible reason for inhibitory effects could be the presence of GABA. It has been reported that GABA has inhibitory effects on the growth of colon carcinoma (Joseph et al., 2002), gastric cancer (Tatsuta et al., 1992), hepatocarcinoma (Sun et al., 2003) and cholangiocarcinoma (Fava et al., 2005). For example, GABA decreased in vitro cholangiocarcinoma growth by both cyclic AMP-dependent regulation of the protein kinase $\mathrm{A}$ and $D$-myo-inositol-1,4,5-triphosphate/ $\mathrm{Ca}^{2+}$-dependent pathways (Fava et al., 2005). The decrease in the growth was significantly correlated with the increase in GABA concentrations of 10 and $100 \mu \mathrm{mol} / \mathrm{L}$. GABA (100 $\mu \mathrm{mol} / \mathrm{L}$ ) also inhibited the migration of cholangiocarcinoma cell lines such as Mz-ChA-1 whereas increasing apoptosis compared with controls (Fava et al., 2005). The GABA concentrations in the L. brevis OPK-3 sample treated cells were calculated to be the ranges of 9.5-38.5 $\mu \mathrm{mol} / \mathrm{L}$. However, authentic GABA showed no inhibitory effects at the concentration rages on the proliferation of the cancer cells (data not shown). Therefore, these data suggested that the L. brevis OPK-3 sample contain other factors contributing the anti-proliferative and apoptosis inducing activity.
Short-chain fatty acids such as butyrate produced by the fermentation process with $\mathrm{LAB}$ could also be key factors for the anti-cancer activities. In fact, butyrate induced cyclooxygenase (COX)-1 expression in the metastatic gastric cancer cells, and thereby COX-1/COX-2 ratio, suggesting a protective role of butyrate in gastric cancer (Mahkonen et al., 2008). In addition, it has been shown that the sodium salt of butyric acid, sodium butyrate, inhibits cell growth and induces apoptosis in a number of cancer cells (Barnard and Warwick 1993; Bernhard et al., 1999; Chopin et al., 2002). It has also been shown that butyrate inhibited the growth of MCF-7 human breast cancer cells in a P53-indpendent manner (Chopin et al., 2002).

In this present study, it is not clear how the treatment of the LAB concentrates could induce p53 gene expression. Many studies showed that the expression of p53 gene can be altered by exogenously added compounds or enzymes in many cancer cells (Atten et al., 2005; Beniston et al., 2001; Kim et al., 2009). For example, recombinant arginine deiminase originating from Lactococcus lactis ssp. Lactis (LADI) increased the expression of $\mathrm{p} 53$ protein in SNU-1 stomach adenocarcinoma cells (Kim et al., 2009). Kim et al. (2009) also showed that arginine deiminase from Lactococcus lactis ssp. Lactis induces $\mathrm{G}_{1}$-phase cell-cycle arrest and apoptosis in SNU-1 stomach adenocarcinoma cells. Furthermore, the inhibition of SNU-1 cell proliferation by the LADI was dose-dependently recovered by adding extra arginine to the cell culture medium (Kim et al., 2009). It has been shown that the arginine deiminase (ADI; EC 3.5.3.6) killed melanomas and hepatocellular carcinomas in vitro and in vivo (Ensor et al., 2002). Rijn et al. (2003) showed that the treatment of arginase inhibitor L-norvaline completely prevented the development of cytotoxicity in the X-ray irradiated H35 hepatoma cells. Thus, candidate products for the inhibitory effects could be ornithine cycle compounds and enzymes such as ornithine, citrulline, ammonia, ADI and arginase. In this regard it is of interest to note that $L$. brevis OPK-3 has potential to produce ornithine (Oh et al., 2010) and citrulline (unpublished data) by depleting arginine, indicating that the strain has the ADI pathways (Kuensch et al., 1974; Liu et al., 2003). Recently, we showed that the kimchi LAB used as a starter for kimchi preparation can grow and produce GABA and ornithine by depleting glutamate and arginine during the fermentation of kimchi (Oh et al., 2010; Seok et al., 2008). Thus, the consumption of kimchi with the kimchi LAB could be beneficial for the anticancer effects. Also, studies to elucidate the underlying 
active compounds and mechanism by which the kimchi LAB with GABA and ornithine producing capacities mediate cancer cell growth inhibition, may reveal great insight into the approach to using the LAB and culture concentrates as pharmaceutical materials.

\section{References}

Aguirre M and Collins MD (1993) Lactic acid bacteria and human clinical infection. J. Appl. Bacteriol. 75, 95-107.

Arena ME, Saguir FM, Manca MC, and Nadra M (1999) Arginine, citrulline and ornithine metabolism by lactic acid bacteria from wine. Int'l J. Food Microbiol. 52, 155-161.

Barnard JA and Warwick G (1993) Butyrate rapidly induces growth inhibition and differentiation in HT29 cells. Cell Growth Differ. 4, 495-501.

Bernhard D, Ausserlechner MJ, Tonko M, Loffler M, Hartmann BL, Csordas A, and Kofler R (1999) Apoptosis indu- ced by the histone deacetylase inhibitor sodium butyrate in human leukemic lymphoblasts. FASEB J. 13, 1991-2001.

Beniston RG, Morgan IM, O'Brien V, and Campo MS (2001) Quercetin, E7 and p53 in papillomavirus oncogenic cell transformation. Carcinogenesis. 22, 1069-1076.

Baum G, Simcha LY, Fridmann Y, Arazi T, Katsnelson H, and Zik M (1996) Calmodulin binding to glutamate decarboxyl- ase is required for regulation and GABA metabolism and normal development in plants. EMBO J. 15, 2988-2996.

Bae MO, Kim HJ, Cha YS, Lee MK, and Oh SH (2009) Ef- fects of kimchi lactic acid bacteria Lactobacillus sp. OPK2-59 with high GABA producing capacity on liver function improvement. J. Korean Soc. Food Sci. Nutr. 38,1499-1505.

Chopin V, Toillon RA, Jouy N, and Bourhis XL (2002) Sod- ium butyrate induces P53-independent, Fas-mediated apoptosis in MCF-7 human breast cancer cells. Brit. J. Pharmacol. 135, 79-86.

Evain-Brion DM, Roger DM, and Job J (1982) Simultaneous study of somatotrophic and corticotrophic pituitary secretions during ornithine infusion test. Clin. Endocrinol. 17, 119122.

Elam RP (1988) Morphological changes in adult males from resistance exercise and amino acid supplementation. J. Sports Medicine Physical Fit. 28, 35-39.

Ensor CM, Holtsberg FW, Momalaski JS, and Clark MA (2002) Pegylated arginine deiminase (ADI-ss PEG $_{20,000} \mathrm{mw}$ ) inhibits human melanomas and hepatocellular carcinomas in vitro and in vivo. Cancer Res. 62, 5443-5450.

Fava G, Marucci L, Glaser S, Francis H, Morrow SD, Benedetti A, Alvaro D, Venter J, Meininger C, Patel T, Taffetani S, Marzioni M, Summers R, Reichenbach R, and Alpini G (2005) $\gamma$-Aminobutyric acid inhibits cholangiocarcinoma growth by cyclic AMP-dependent regulation of the protein kinase A/extracellular signal-regulated kinase1/2 pathway. Cancer Res. 65, 11437-11446.

Hur HJ, Lee KW, Kim HY, Chung DK, and Lee HJ (2006) In vitro immunopotentiating activities of cellular fractions of lactic acid bacteria isolated from Kimchi and bifidobacteria. J. Microbiol. Biotechnol. 16, 661-666.

Joseph J, Niggemann B, Zaenker KS, and Entschladen F (2002) The neurotransmitter $\gamma$-aminobutyric acid is an inhibitory regulator for the migration of SW 480 colon carcinoma cells. Cancer Res. 62, 6467-6469.

Kim SJ (2005) Potential probiotic properties of lactic acid bacteria isolated from kimchi. Food Sci. Biotechnol. 14, 547-550.

Kim JM, Kim KH, Kim SY, Park YS, Seo MJ, and Yoon SS (2005) Isolation and characterization of antilisterial actic acid bacteria from kimchi. Food Sci. Biotechnol. 14, 503-508.

Krogsgaard-Larsen P. GABA receptors. In: Williams, M., Glennon, R.A., Timmermans, P.M.W.M. (Eds.), (1989) Receptor Phamacology and Funtion. Marcel Dekker Inc., New York, pp. 349-383.

Kawai Y, Nakagawa Y, Matuyama T, Akagawa K, Itagawa K, Fukase K, Kusumoto S, Nishijima M, and Yano I (1999) A typical bacterial ornithine-containing lipid N-a-(D)-[3-(hexadecanoyloxy)hexadecanoyl]-ornithine is a strong stimulant for macrophages and a useful adjuvant. FEMS Immunol. Med. Microbiol. 23, 67-73.

Kawai Y, Takasuka N, Inoue K, Akagawa K, and Nishijima M (2000) Ornithine-containing lipids stimulate CDl4-dependent TNF-a production from murine macrophage-like J774.1 and RAW 264.7 cells. FEMS Immunol. Med. Microbiol. 28, 197-203.

Kuensch U, Temperli A, and Mayer K (1974) Conversion of arginine to ornithine during malolactic fermentation in red swiss wine. Am. J. Enol. Vitic. 25, 191-193.

Kim DS (2002) Chracteristics of the bacteriocin from Lactobacillus sp. Oh-B3. Korean J. Microbiol. Biotechnol. 30, 184-188.

Kim JE, Kim SY, Lee KW, and Lee HJ (2009) Arginine deiminase originating from Lactococcus lactis ssp. lactis American type culture collection (ATCC) 7962 induces $\mathrm{G}_{1}$-phae cell-cycle arrest and apoptosis in SNU-1 stomach adenocarcinoma cells. Brit. J. Nutrition 102, 1469-1476.

Lee JS, Lee KC, Ahn JS, Mheen TI, Byun YR, and Park YH (2002) Weissella. koreensis sp. nov., isolated from kimchi. Int'l J. Syst. Evol. Microbial. 52, 1257-1261.

Leventhal AG, Wang Y, Pu M, Zhou Y, and Ma Y (2003) GABA and its agonists improved visual cortical function in senescent monkeys. Science 300, 812-815.

Liu SQ, Holland R, and Crow VL (2003) The potential of dairy lactic acid bacteria to metabolise amino acids via non-transaminating reactions and endogenous transamination. Int'l. J. Food Microbiol. 86, 257-269.

Mody I, Dekoninck Y, Otis TS, and Soltesz I (1994) Bringing the cleft at GABA synapses in the brain. Trends Neurosci. 17, 517-525.

Mosmann TJ (1983) Rapid colorimetric assay for cellular growth and survival: application to proliferation and cytotox- icity assays. Immunol. Methods 65, 55-63.

Mahkonen A, Putaala H, Mustonen H, Rautonen N, and Puolakkainen P (2008) Lactobacillus acidophilus 74-2 and butyrate induce cyclooxygenase (COX)-1 expression in gastric cancer cells. Immunopharmacol Immunotoxicol. 30, 503-518. 
Oh SH, Park KB, Seok JH, Kim YH, and Lee MK (2010) Strain for high ornithine production, starter for kimchi fermentation, and method for kimchi preparation with high content of ornithine. Korea patent (registered). 10-0962580.

Park KB and Oh SH (2004) Cloning and expression of a fulllength glutamate decarboxylase gene from Lactobacillus plantarum. J. Food Sci. Nutr. 9, 324-329.

Park KB and Oh SH (2005) Production and characterization of GABA rice yogurt. Food Sci. Biotechnol. 14, 518-522.

Park KB and Oh SH (2006) Enhancement of $\gamma$-aminobutyric acid production in Chungkukjang by applying a Bacillus sub-tilis strain expressing glutamate decarboxylase from Lactobacillus brevis. Biotechnol. Lett. 28, 1459-1463.

Park KB and Oh SH (2007) Cloning, sequencing and expression of a novel glutamate decarboxylase gene from a newly isolated lactic acid bacterium, Lactobacillus brevis OPK-3. Bioresource Technol. 98, 312-319.

Rhee CH and Park HD (1999) Isolation and characterization of lactic acid bacteria producing antimutagenic substance from Korean kimchi. Korean J. Microbiol. Biotechnol. 27, 15-22.

Robinson LE, Bussier FI, Boucher J. Le, Farges MC, Cynober LA, Field CJ, and Baracos VE (1999) Amino acid nutrition and immune function in tumour-bearing rats: a comparison of glutamine-, arginine- and ornithine 2-oxoglutaratesupplemented diets. Clinical Science 97, 657-669.

Rijn JV, Berg JVD, Teerlink T, Kruyt FAE, Schor DSM, Renardel de Lavalette AC, Berg TKVD, Jakobs C, and Slotman $\mathrm{BJ}$ (2003) Changes in the ornithine cycle following ionizing radiation cause a cytotoxic conditioning of the culture med- ium of H35 hepatoma cells. Brit. J. Cancer. 88, 447-454.

Seok JH, Park KB, Kim YH, Bae MO, Lee MK, and Oh SH (2008) Production and characterization of kimchi with enhanced levels of $\gamma$-aminobutyric acid. Food Sci. Biotechnol. 17, 940-946.

Sun D, Gong Y, and Kojima H (2003) Increasing cell membrane potential and GABAergic activity inhibits malignant hepatocyte growth. Am. J. Physiol. 285, G12-19.

Tatsuta M, Iishi H, Baba M, and Taniguchi H (1992) Attenuation by the GABA receptor agonist baclofen of experimental carcinogenesis in rat colon by azoxymethane. Oncology 49, 241-245.

Thirabunyanon M, Boonprasom P, and Niamsup P (2009) Probiotic potential of lactic acid bacteria isolated from fermented dairy milks on antiproliferation of colon cancer cells. Biotechnol. Lett. Apr. 31, 571-576.

Ueno H (2000) Enzymatic and structural aspects on glutamate decarboxylase. J. Molecular Catalysis. 10, 67-79.

Wernerman J and Hammarqvist F (1987) Ornithine-a-ketoglutarate improves skeletal muscle protein synthesis as assessed by ribosome analysis and nitrogen use after surgery. Ann. Surgery. 206, 674-678.

$\mathrm{Yu}$ JJ and Oh SH (2011) $\gamma$-Aminobutyric acid production and glutamate decarboxylase activity of Lactobacillus sakei OPK 2-59 isolated from kimchi. Korean J. Microbiol. 47, 316-322.

Yu JJ, Park HJ, Kim SG, and Oh SH (2009) Isolation, identification, and characterization of Weissella strains with high ornithine producing capacity from kimchi. Kor. J. Mirobiol. 45, 339-345. 